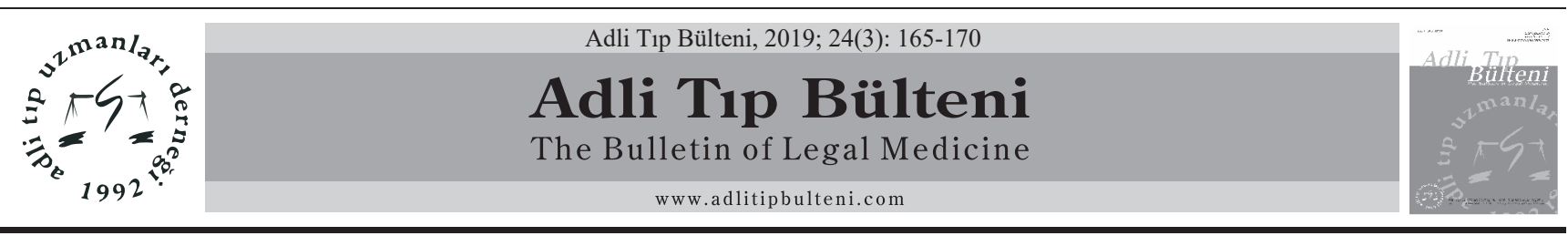

ARAŞTIRMA / RESEARCH ARTICLE

\title{
Medeni Kanun Kapsamında Erken Evlilik Yapan Olguların Sosyodemografik Özellikleri: Tek Merkez Çalışması
}

\section{Sociodemographic Characteristics of Early Marriage Cases According to The Civil Code: A Single Center Study}

Mustafa Talip Şener*, Büşra Baydemir Kılınç

\section{$\ddot{\mathbf{O} z}$}

Amaç: Türk Medeni Kanunu göre erkek ve kadın on yedi yaşını doldurmadıkça evlenemez. Ancak, hâkim olağanüstü durumlarda ve pek önemli sebeple on altı yaşını doldurmuş olan erkek veya kadının evlenmesine izin verebilir. Bu çalışmada Medeni Kanun'a göre erken evlilik için müracaat ederek, adli tıbbi değerlendirmesi yapılan olgulara ait sosyodemografik özelliklerin incelenmesi amaçlandı.

Gereç ve Yöntem: Türk Medeni Kanun'un 124. Maddesine göre erken evlilik için müracaat eden ve adli tıbbi değerlendirmesi yapılan 39 olgu çalışma kapsamında ele alınarak, yaş, cinsiyet, eğitim ve evlilik ile ilişkili sosyodemografik özellikleri araştırıldı.

Bulgular: Olguların tümü kadın olup, \%53,8'i $(n=21)$ gerçek doğum tarihleri ile nüfus kayıtlarının farklı olduğunu belirtti. Tüm olguların kemik yaş tespiti yapıldı ve \%43,6'sının $(\mathrm{n}=17)$ kimlikteki yaşlarından ortalama $1,9( \pm 0,9$; min:1, maks:4) yaş büyük bulundu. Olguların \%69,2'si (n=27) ilköğretim mezunu olup, \%94,9'u (n=37) eğitimini evlilik sürecinden bağımsız olarak daha önceden bırakmıştı. Olguların \%46,2'sinin $(n=18)$ evlilik yaptığı ve $\% 48,7$ 'sinin ( $n=19)$ gebe olduğu belirlendi.

Sonuç: Bölgemizde medeni kanun kapsamında erken evlilik için müracaat eden olguların tümü kadın olup, önemli bir kısmı eğitimlerini ilköğretim seviyesinde bırakmıştır. Olguların neredeyse yarısının gerçek doğum tarihleri ile kimlik yaşları farklı olup ortalama iki yaş küçüktür.

Anahtar Kelimeler: Erken Evlilik; Medeni Kanun; Yaş.

\section{Abstract}

Objective: According to the Turkish Civil Code, men and women cannot marry unless they are 17 years old. However, the judge may allow the marriage of men or women who have reached the age of 16 for extraordinary and so important reasons. The aim of this study was to examine the sociodemographic characteristics of early marriage appliers according to civil law who underwent a forensic medical assessment.

Materials and Methods: According to article 124 of Turkish civil law, 39 patients who applied for early marriage and who underwent forensic medical assessment were investigated for sociodemographic characteristics related to age, gender, education and marriage.

Results: All of the cases were female and $\% 53,8(\mathrm{n}=21)$ stated that the actual birth dates and population records were different. Bone age was determined in all cases, \%43,6 ( $\mathrm{n}=17)$ were found to be older than identity age in the average of $1,9( \pm 0,9$, min: 1 , max: 4$)$ years. $\% 69.2(n=27)$ of the cases were primary school graduates and $\% 94,9(n=37)$ had previously left their education independent of the marriage process. It was determined that $\% 46,2(n=18)$ of the cases were married and \%48,7 $(\mathrm{n}=19)$ were pregnant.

Conclusions: In our region, all of the cases applied for early marriage according to civil law are women and a significant part of them left their education at the primary school level. Almost half of the cases are different from their actual birth dates and identity ages in which are 2 years younger in the average.

Keywords: Early; Marriage; Civil Code; Age.
DOI: $10.17986 / \mathrm{blm} .2019252265$

Mustafa Talip Şener: Doç. Dr., Atatürk Üniversitesi Tıp Fakültesi, Adli Tıp Anabilim Dalı, Erzurum Eposta: mustafatalipsener@gmail.com ORCID iD: https://orcid.org/0000-

0002-1295-7710

Büşra Baydemir K1lıç̧: Arş. Gör. Dr., Atatürk Üniversitesi Tip Fakültesi, Adli Tıp Anabilim Dalı, Erzurum Eposta: busrabaydemir@gmail.com ORCID iD: https://orcid.org/00000001-8114-5866

Bildirimler/ Acknowledgement: Yazarlar bu makale ile ilgili herhangi bir çıkar çatışması bildirmemişlerdir. The authors declare that they have no conflict of interests regarding content of this article.

Finansal Destek/Support Resources Yazarlar bu makale ile ilgili herhangi bir finansal destek bildirmemişlerdir. The Authors report no financial support regarding content of this article.

*Sorumlu Yazar/Corresponding Author:

Geliş: 22.01 .2019

Düzeltme: 13.03.2019

Kabul: 18.04.2019

p-ISSN: $1300-865 \mathrm{X}$

e-ISSN: $2149-4533$ 


\section{Giriş}

Ailenin temellerinin oluşmasında önemli bir rol oynayan evlilik, iki insanın duygusal, ekonomik ve sosyal olarak birlikte yaşamasını düzenleyen ve yetkili kanuni merci önünde yapılan çift taraflı anlaşmadır (1). Türk Medeni Kanunu'na göre evliliğin yasal olarak kurulması için bireylerin ayırt etme gücünün yanında, 17 yaşını tamamlaması gerekmektedir. Medeni Kanun'un 124. maddesi 'erkek ve kadın on yedi yaşını doldurmadıkça evlenemez. Ancak, hâkim olağanüstü durumlarda ve pek önemli sebeple on altı yaşını doldurmuş olan erkek veya kadının evlenmesine izin verebilir. Olanak bulundukça karardan önce ana ve baba veya vasi dinlenir' şeklinde düzenlenmiştir. Türk Medeni Kanunu'na göre kadın ya da erkek, on altı yaşını doldurmamış ise hiçbir şekilde evlenmelerine izin verilmemektedir. Ülkemizde Medeni Kanun'un öngördüğü şekilde hâkim kararıyla yapılmış olan erken evliliklerin oranının $\% 15,5$ olduğu belirtilmektedir (2). Medeni Kanun kapsamında erken evlilik için mahkemeye müracaat eden olguların evlenmesine engel hastalığ1nın, ayırt etme gücünün olup olmadığının belirlenmesi amacıyla tıbbi değerlendirme istenmektedir. Bu çalışmada erken yaşta evlilik için Türk Medeni Kanun'un 124. maddesine göre müracaat eden ve adli tıp anabilim dalına gönderilerek tıbbi değerlendirmesi yapılan olgular incelenerek, bölgemize ait medeni kanun kapsamında erken evliliklere ait sosyodemografik özelliklerin incelenmesi amaçlandi.

\section{Gereç ve Yöntem}

Adli Tip Anabilim Dalına 01.01.2015-31.12.2018 tarihleri arasında Türk Medeni Kanun'un 124. maddesine göre adli tıbbi değerlendirmesi yapılan 39 olgu çalışma kapsamında ele alınarak yaş, cinsiyet, eğitim, evlilik ile ilişkili demografik özellikleri araştırıldı. Evlilik izni için gönderilen ve kimlik yaşının doğru olmadığını belirten olguların fiziksel gelişimi doğrulamak ve kemik yaş tahmini için; fiziksel gelişim özellikleri ile birlikte diş ve kemik gelişimi değerlendirildi. Bu amaçla olguların fiziksel gelişimine uygun olarak el-el bileği, omuz, lateral dirsek, yan ve AP pelvis direk grafileri çekildi. Kemiklerin epifiz hatlarının kapanma derecelerine göre Tanner-Whitehouse Atlası, Radyolojik Yaş Tayini ve Adli Tıpta Yaş Tayini (ATYT) kitabı mukayeseli olarak kullanılarak radyoloji uzmanı görüşü ile birlikte yaş tahmini yapıldı (3-5). Çalışmadan elde edilen verilerin istatistiksel değerlendirilmesinde kategorik veriler frekans ve yüzde cinsinden, sürekli veriler ise ortalama olarak \pm standart sapma cinsinden özetlendi. İstatistiksel analizlerde SPSS (Statistical Package for Social Sciences) for Windows 20.0 programı kullanıldı. Çalışma için Atatürk
Üniversitesi Girişimsel Olmayan Klinik Araştırmalar Etik Kurulu'ndan 05.05.2017 tarih ve 14 karar sayılı etik onay alındı.

\section{Bulgular}

Medeni kanun kapsamında erken evlilik için müracaat edenlerin tümü kırsal bölgede yaşayan kadın olgular olup, kimlik yaş ortalamaları $17( \pm 0,2)$ olarak bulundu. Anamnez bilgisine göre \%53,8'i (n=21) gerçek doğum tarihleri ile nüfus kayıtlarının farklı olduğunu ve nüfus kayıtlarındaki yaşlarından ortalama 2 yaş $(\mathrm{sd} \pm 13,9$; min:0,2 - maks:5) büyük olduklarını belirttiler. Tüm olguların yaş tahminine yönelik fizik muayenesi ve gebe olmayanların radyolojik tetkikleri yapıldı. Tüm olguların kemik yaş tahmini yapıldığında \%43,6'sının ( $\mathrm{n}=17)$ kimlikteki yaşlarından ortalama 1,9 ( $\mathrm{sd} \pm 0,9$; min:1 - maks:4) yaş büyük oldukları bulundu. Kimlik yaşına göre kemik yaşı küçük olan herhangi bir olgu saptanmadı. Olguların kemik yaş tespitlerine göre $\% 28$,2'sinin ( $\mathrm{n}=11)$ muayene edildiği tarihte 18 yaşını tamamladığı belirlendi.

Olguların \%69,2'si (n=27) ilköğretim eğitim mezunu olup, \%5,1'inin (n=2) gebe olduğu için evlilik yapmak üzere eğitimini bıraktığı, diğerlerinin ise kendi istekleri, okula ulaşım zorlukları, ders başarılarının düşüklüğü ve ailenin maddi sıkıntıları gibi nedenlerle evlilik sürecinden bağımsız olarak eğitimlerini daha önceden bıraktığı bulundu.

Olguların tümünün söz, nişan, yüzük takma gibi evlilik öncesi geleneksel törenleri yaptığ 1 ve bunlardan $\% 46,2$ 'sinin $(n=18)$ muayenemizden ortalama 4,7 ay önce düğün ve dini nikah yaptıkları, çevrelerine kendilerini evli olarak duyurdukları bulundu. Tümü evliliğin kendi istekleri ile gerçekleştiğini ve \%48,7'sinin $(n=19)$ gebe olduğu belirlendi.

Olguların annelerin ortalama evlilik yaşının 18,4 $( \pm 3,0)$ olduğu, ebeveynlerden \%10,2'si (n=4) kızlarının evlenmesinin erken olduğunu düşündüklerini, ancak gebelik sebebi ile kabul ettiklerini belirtti.

Olguların evlenmek istedikleri kişilerin ortalama yaşı 24,0 ( $\pm 2,7$; min:19 - maks:30) olup evlenmek istedikleri kişi ile yaş farkının ortalama $6,1( \pm 2,8)$ olduğu ve evlenmek istedikleri kişiyi ortalama 1,9 yıldan beri $( \pm 1,4$; min:1 - maks:6) tanıdığ $1, \% 61,5$ 'i (n=24) evlenmek istedikleri kişiler ile aynı köy/mahalleden, iş veya arkadaş ortamlarından tanıştıklarını, \%25,6'si (n=10) akrabası olduğunu belirtti. Akrabalık durumu incelendiğinde, olguların hiçbirinde birinci ya da ikinci derece kuzen akrabalı̆g 1 olmadığı, kan bağı olan uzak akrabaları olduğu öğrenildi. Evlenmek istedikleri kişilerin \%92,3'ünün $(n=36)$ bir işte çalıştı̆̆ 1 ve \%59'u (n=23) evlenmek istedikleri kişilerin ailesi ile birlikte aynı evde evliliklerini sürdüreceklerini belirttiği öğrenildi. 
Olguların \% 79,5'i (n=31) öz anne ve babası ile birlikte yaşadığı ve aile içi bir probleminin olmadığı öğrenildi. Diğer 8 olgunun anne ya da babadan birinin öldüğü veya boşandığı, bunlardan 3 olgunun üvey anne ya da baba ile yaşadığı belirlendi. Muayenede olguların tümünde psikopatolojik herhangi bir bulgu olmadığı, fiziksel ve ruhsal olarak gelişimlerinin yaşları ile uyumlu olgunlukta olduğu, ayırt etme gücüne sahip oldukları yönünde tıbbi kanaat belirtildi. Olgulara ait demografik veriler Tablo 1'de gösterildi.

\section{Tartışma}

Evliliğin on sekiz yaş altında gerçekleşmesi erken evlilik olarak tanımlanmakta, bu evlilikler sosyolojik olarak çocuk evliliği olarak değerlendirilmektedir $(6,7)$. Çocuk evliliği, ülkemizde ve dünyada devam eden yaygın bir sorundur. Tüm dünyadaki kızların \%34'ünün 18 yaşına gelmeden evlendiği bildirilmektedir (8). Erken evlilikler dünyada ilk kez çocuk haklarının korunması kapsamında ele alınarak, çocuk haklarının ihlali olarak değerlendirilmeye başlanmıştır $(9,10)$. Tüm dünyada erken evliliklerle ilgili güvenilir ve sağlıklı istatistikler elde edilememekle birlikte; 20-24 yaş aralığındaki kadın grubu içinde 18 yaş altı evliliklerin Nijer (\%75), Çad (\%68), Orta Afrika Cumhuriyeti (\%68), Bangladeş (\%66), Gine (\%63), Mozambik (\%56) gibi gelişmişlik düzeyi düşük ülkelerde en yüksek oranlarda görüldüğü, Türkiye'de ise bu oranın \%14 oranında olduğu ve Avrupa ülkeleri arasında Gürcistan'dan sonra ikinci sırada geldiği belirtilmektedir (11). Türkiye'de Doğu ve Güneydoğu Anadolu Bölgelerinde erken evlilik oranlarının batı illerine göre daha yüksek olup, Türkiye İstatistik Kurumu (TÜİK) 2017 yılı yaş gruplarına göre ilk defa evlenen kadın istatistikleri incelendiğinde; 16-19 yaş grubu kadınların Türkiye genelinde $\% 18,6$ olduğu görülmektedir (12).

Tablo 1. Olgulara ait sosyodemografik özellikler

\begin{tabular}{|c|c|c|c|}
\hline & & $\mathrm{n}$ & $\%$ \\
\hline \multirow{2}{*}{$\begin{array}{l}\text { Anamnez bilgisine göre kimlik yaşı ile gerçek } \\
\text { doğum tarihinin durumu }\end{array}$} & Fark yok & 18 & 46,2 \\
\hline & Fark var & 21 & 53,8 \\
\hline \multirow{2}{*}{$\begin{array}{l}\text { Değerlendirme sonrası kimlik yaşı ile kemik yaşı } \\
\text { durumu }\end{array}$} & Fark yok & 22 & 56,4 \\
\hline & Fark var & 17 & 43,6 \\
\hline \multirow[t]{2}{*}{ Evlilik durumu } & Düğün yapmış & 18 & 46,2 \\
\hline & Ailelerin katılımı ile söz-nişan yapmış & 21 & 53,8 \\
\hline \multirow[t]{2}{*}{ Gebelik durumu } & Gebe değil & 20 & 51,3 \\
\hline & Gebe & 19 & 48,7 \\
\hline \multirow[t]{4}{*}{ Ebeveyn durumu } & Annesi ölen & 2 & 5,1 \\
\hline & Babası ölen & 2 & 5,1 \\
\hline & Anne baba boşanan & 4 & 10,3 \\
\hline & Birlikte & 31 & 79,5 \\
\hline \multirow[t]{4}{*}{ Eğitim durumu } & İlköğretim 1. kısımdan okulu bırakan & 5 & 12,8 \\
\hline & İlköğretim 2. kısımdan okulu bırakan & 22 & 56,5 \\
\hline & Liseye devam ederken okulu bırakan & 10 & 25,6 \\
\hline & Açık öğretime devam eden & 2 & 5,1 \\
\hline \multirow[t]{5}{*}{ Evleneceği kişi ile tanışma şekli } & Görücü usulü & 4 & 10,3 \\
\hline & Akraba & 10 & 25,6 \\
\hline & İnternet ortamında & 1 & 2,6 \\
\hline & İş ve arkadaş ortamında & 9 & 23 \\
\hline & Komşusu veya aynı köy/mahalle & 15 & 38,5 \\
\hline
\end{tabular}


Türk Medeni Kanunu'na göre erkek ve kadının on yedi yaşını doldurmadıkça evlenemeyeceği, ancak hâkimin olağanüstü durumlarda ve pek önemli sebeple on altı yaşını doldurmuş olan erkek veya kadının evlenmesine izin verebileceği belirtilmiştir. Kanunda belirtilen olağanüstü bir durumun ve pek önemli bir sebebin bulunup bulunmadığı hâkimin takdirindedir. Uygulamada kadının evlilik dışında gebe kalması, nişanlılardan birinin ölüm tehlikesi içinde olması, karı koca gibi yaşama, kadının anne ve babasını kaybetmiş olması gibi durumların pek önemli bir sebep ve olağanüstü bir durum kapsamında değerlendirildiği görülmektedir (2). Kanuna göre anne, baba veya vasinin dinlemesi şart olmayıp, yasal temsilci evliliğe karşı olsa bile olağanüstü durumun veya pek önemli sebebin olması durumunda evlenmeye izin verilebildiği belirtilmektedir (2).

Türkiye'de yaygın olarak evliliklerde resmi ve dini nikâh birlikte yapılmaktadır. Ülkemizde 18 yaşından önce evlenenlerin \%28,1'inin her iki nikâhı beraber yaptığı, sadece dini nikâhla yapılan evliliklerde bu oranın \%44,7'ye kadar yükseldiği, ailelerin kız çocuklarını evlendirmek isterken birçok nedenle, yasal olarak evlenme yaşı gelene kadar dini nikâh ile evlilik yoluna başvurarak yasal yolların dışına çıktığı ve bu durumun toplumca kabul gördüğü belirtilmektedir (13). Çalışmamızda da benzer şekilde olguların \%46,2'sinin $(n=18)$ dini nikah yaparak evlilik yaptığı bulundu. Erken evliliklerinin kayıt dışı gerçekleşmesi, kadınları evliliğin getirdiği kanuni haklardan yoksun bırakabilmektedir. Resmi nikâhla evli olamama; miras hukukunun kadına sunduğu haklardan yararlanamaya, çok eşlilik riskine ve erken yaşta zorla evlendirilme riskine maruz kalmaya yol açabilmektedir. Bu sebeplerle Avrupa Birliği Üyesi bazı ülkelerde gebelik ya da kanunlarda açık bir şekilde tanımlanmayan istisnai durumlarda erken evliliğin alt yaş sınırının ve hâkim kararının gözetildiği, en düşük evlenebilme yaşının 16 olabildiği görülmektedir (14). Dünya genelinde ise 146 ülkede 18 yaş altı kızlar ve 52 ülkede 15 yaş altı kızlar ebeveyn rızası veya geçerli bir otoritenin onayı ile evlenebilmektedir (15). TÜİK 2001-2017 yılları arasındaki evlilik verileri incelendiğinde; 2001 yılında evlenen tüm kadınlar içinde 16-19 yaş grubunda evlenen kadın oranı yaklaşık \%32,6'dan \%18,6'e gerilediği, erkeklerde ise bu oranın üçte bir azalarak yaklaşık \%0,5'e gerilediği bulunmuştur (12). Bu sonuçlar erken evliliklerde bir azalmakla olduğunu, ancak erken evliliklerin öncelikle kadınlar için bir sorun olarak devam ettiğini göstermektedir. Nitekim çalışmamızda da Türk Medeni Kanunu çerçevesinde erken evlilik için müracaat eden olgulardan hiçbir erkek yoktu.
Nüfus kaydı çocuğun yasal statüsünü temin etmek, temel haklardan ve hizmetlerden faydalanmasını sağlamak için gereklidir. Ülkemizde özelikle kırsalda ve doğuda daha çok olmak üzere nüfus kayıtlarının tam olmadığı ve Türkiye Nüfus Sağlık Araştırması (TNSA) 2013 verilerine göre çocukların \%1'inin nüfus kayd1nın okula kayıt, evlilik, askerlik gibi yasal zorunluluğun olduğu dönemlerde yapıldığ 1 belirtilmektedir (16). Çalışma kapsamında incelenen olguların doğum yılları dikkate alınarak TNSA 1998 sonrasında doğan çocukların verileri incelendiğinde; bu dönemde çocukların $\% 16$ 'sının nüfus cüzdanının olmadığ 1 , bu oranın $\% 17,2$ ile kız çocuklarında daha fazla olduğu ve bu çocukların daha çok ülkemizin doğusunda ve kırsal bölgelerde yaşadığı belirtilmektedir (17). Evlilik için resmi işlemler öncelikle kimlik yaşına göre yapılmaktadır. Ancak nüfus kayıtlarının sağlıklı olmadığı durumlarda yaş tespiti istenebilmektedir. Bu amaçla en sık kullanılan ve değerli veriler sunan kemik yaşı tahmini yöntemi kullanılmakla birlikte; genetik yapı, hormonal ve çevresel faktörler, beslenme gibi pek çok değişken kemiklerin gelişimini etkileyebilmektedir. Ülkemizde Şemsi Gök ve arkadaşları tarafından oluşturulmuş Gök Atlası sıklıkla kullanılmaktadır (18). Yaş tahmininde Türk kemik yaş standartlarına göre hazırlanmış bir atlas bulunmaması ve kemik olgunlaşmasının bireysel, cinsel, kalıtsal, toplumsal ve sosyoekonomik faktörlere göre değişiklik gösterdiğinden kesin olarak yaş tespitinde bulunmak zordur (1821). Kemik yaş belirlemeleri kesin olmasa da olguların \%53,8'i gibi önemli bir kısmı gerçek yaşlarının, kimlikte kayıtlı olan yaştan 2-60 ay arasında değişen aralıklarda olmak üzere daha büyük olduklarını belirtmiş, bu olguların kemik yaş tahmini yapıldığında \%43,6'sının kimlik yaşlarından ortalama 2 yıl daha büyük oldukları bulunmuştur. Çalışmamızda olgularda yüksek oranda nüfus kayıtlarına göre yaş farkının olması; olguların tümünün kırsal bölgelerden gelmesinin ve nüfus kayıtlarının sağlıklı olmamasının bir sonucu olarak değerlendirilebilir. Ülkemizde nüfus kaydı zamanında yapılmayan çocuk sayılarında azalma görülse de, nüfus kaydının zamanında yapılmaması ileri de bir kısım evlilik müracaatlarının, erken evlilik müracaatı gibi değerlendirilmesine de neden olabilmektedir.

Erken evliliklerin nedenleri arasında daha çok ailenin maddi gelirinin azlığı, sosyokültürel seviyenin düşüklüğü, gelenekler, evlilik dışı gebelik durumları, aile içi şiddet gösterilmekte, ayrıca çeşitli kültürel, dinsel, ekonomik ve ailesel özellikler toplumsal olarak erken yaşta evliliği meşru kılabilmektedir $(7,22,23)$. Olguların doğum yılları dikkate alınarak TÜİK verilerine 
göre ilk defa evlenen kadın istatistikleri incelendiğinde; Türkiye genelinde kadın evlilik yaşının ortalama 21 ile 25,6 (ortalama yaş: 23,2 ) arasında değiştiği görülmektedir (13). Çalışmada olguların annelerinin ortalama evlilik yaşının, Türkiye'nin ve bölgemizin kadın evlilik yaş ortalamasından küçük olduğu belirlendi. Ebeveynlerin erken yaşta evlenmesi, çocuklarının da erken evlik yapmasını kabullenmeye ve erken evliliklerin bu ailelerde daha yaygın olmasina neden olan bir durum olabilir.

2016 Türkiye Aile Yapısı Araştırma (TAYA) verilerine göre, evliliklerin \%59,9'unun görücü usulü gerçekleştirildiği ve ailelerin erken evliliklerde akraba evliliklerine yaşlı kuşağın kendi gelecek kaygısı, kızlarının mutluluğunu garanti altına alma, akraba oldukları için kızlarının eziyet görmeyeceğini düşünme gibi nedenlerle sıcak baktıkları belirtilmektedir (24).

Akrabalık, iki bireyin aynı atadan gelme durumu; akraba evliliği ise eşler arasında kan bağı bulunması, yani aynı atadan gelen kişilerin evlenmesidir. Ülkemizde birinci derece kuzen evlilikleri (kardeş çocuklarının evlilikleri) en sık rastlanan akraba evliliği şeklidir. İkinci derece kuzen evliliği (kuzen çocuklarının evliliği) ise daha az sayıdadır (25). Çalışmamızda olguların akraba olarak belirttikleri kişilerin, kan bağı olan uzak akrabaları olduğu görüldü. TÜIK 2016 y1lı eşi ile akraba olma duru$m u$ verilerine göre, Türkiye genelinde akraba evliliğinin \%23,2 olduğu, Kuzeydoğu Anadolu Bölgesinde ise bu oranın \%25,6 olduğu görülmektedir (12). Çalışmamızda da akraba evliliği oranı bölgemiz ile benzer olarak bulundu. Olguların daha çok yakın çevresindeki kişilerle ve ortalama 1,9 yıl tanışma dönemi sonrasında evliliği gerçekleştiği veya gerçekleştirmeyi planladıkları görüldü. Çalışmaya katılan olguların evlenmek istedikleri kişilerin ortalama yaşı 24 olup aralarında ortalama 6 yıl yaş farkı bulundu. 2017 TÜİK verilerine göre Türkiye geneli ve bölgemizin eşlerin yaş farkına göre evlenme durumları benzer bulundu (12).

Genel olarak eğitim seviyesi artıkça erken evliliklerin azaldığı, eğitim seviyesi azaldıkça erken evliliklerde $\operatorname{arttığı~bilinmektedir~(7).~TAYA~verilerine~göre~hiç~oku-~}$ la gitmeyen kızlarda 18 yaşın altında evlilik oranı $\% 40$ iken, bu oran orta öğretimden mezun olanlarda \%14'e ve liseyi tamamlayanlarda \%4'e düşmektedir (16). Çalışmamızda da olguların çok önemli bir kısmı ortaokul mezunu olup, \%25,6'sının lise eğitimini tamamlamadan bıraktığı bulundu. Erken evlilikler, devam eden eğitim sürecini sonlandırılabilmektedir. Çalışmamızda iki olgunun ailelerinden habersiz kaçarak evlenmesi ve gebe kalması nedeni ile eğitimlerini sonlandırdıkları görüldü. Ancak diğer olguların kendi istekleri, okula ulaşım zorluğu, ders başarılarının düşüklüğü ve ailenin maddi sıkıntısı gibi nedenlerle eğitimlerini evlilik sürecinden bağımsız olarak önceden bıraktıkları belirlendi. Bu bulgulara göre erken evlilik, bu olgular için eğitimin bırakılmasına neden olan bir durum olmasa da eğitime devam etmemenin erken evliliğe zemin hazırlayan önemli bir faktör olduğunu göstermektedir.

TAYA verilerin göre ülkemizde tek kişilik çekirdek hanelerden, geniş ailelere kadar oldukça farklı aile biçimleri olup, hane halkı reisi, eşi, evli çocukları ve/veya evli kardeşleri ile aynı hanede yaşamın sürdüğü ataerkil geniş aile yapısının Orta ve Ortadoğu Anadolu bölgelerde yoğunlaştı̆ı görülmektedir (26). Çalışmamızda olguların $\% 59$ 'u $(\mathrm{n}=23)$ ataerkil geniş aile modeline uygun olarak eşlerinin ailesi ile birlikte en azından evliliklerinin ilk yıllarında yaşayacağını belirtmiş̧ir. Öncelikle ekonomik nedenler olmak üzere, kültürel faktörlerin ve evliliğin getirdiği sorumlulukların erken yaşta kaldırılamayacağı düşüncesinin özellikle evliliğin ilk yıllarında bu aile yaşamı modelini desteklediği düşünülebilir.

Ailede ebeveynlerde boşanma, ayrı yaşama ya da ölüm gibi nedenlerle karı veya kocadan birinin ya da her ikisinin bulunmaması parçalanmış aile olarak tanımlanır. Parçalanmış ailelerde çocukların çeşitli psikososyal sorunlar yaşadığı, özellikle ergenlik döneminin daha zor geçtiği ve parçalanmış ailelerde yetişen ergenlerin sosyalleşme sürecinin başarısız ilerlediği belirtilmektedir $(27,28)$. Çalışmamızda 8 olgunun ebeveynlerden birinin ölümü, boşanması gibi parçalanmış aile ortamında yaşadığı ve bunlardan 3'ünün üvey anne ya da baba ile yaşadığg görüldü. Aile ortamında ki bu durum, bireyleri erken evliliğe iten başka bir sebep olabilir.

\section{Sonuç}

Sonuç olarak bulgularımıza göre bölgemizde medeni kanun kapsamında erken evlilik için müracaat eden olguların tümü kadın olup, eğitimlerini ilköğretim seviyesinde bırakan, kırsal bölgede yaşayan bireylerdir. Olguların ebeveynleri de ülkemiz ortalamalarına göre erken evlilik yapmıştır. Olguların yaklaşık yarısının nüfusa ortalama iki yaş küçük kayıt edildiği ve yaş düzeltmesi yapılması halinde en az dörtte birinin on sekiz yaşını tamamlayacağı bulunmuştur. Olgular eğitimlerini evlikten bağımsız olarak önceden bırakmış ise de eğitimin sürdürülmemesi erken evlilikleri kolaylaştıran önemli bir faktör olduğu ve eğitimin sürdürülmesinin erken evlilikleri azaltabileceği değerlendirilmiştir. 


\section{Kaynaklar}

1. Yıldız MA, Çevik GB. A Study on Marital Satisfaction and Life Satisfaction With Married İndividuals. International Journal of Human Sciences 2016;13(1):227-42. DOI: https://doi.org/10.14687/ijhs.v13i1.3417

2. Dural M, Öğüz T, Gümüş MA. Türk özel hukuku.14.bask1. İstanbul: Filiz Kitabevi; 2018.

3. Tanner JM, Whitehouse RH, Cameron N, et al. Assesment of skeletal maturity and prediction of adult height (TW2 method). 2nd ed. London:Academic Pres; 1983. 22-37 and 50-58.

4. Yekeler E. Adli tıpta radyolojik yaş tayini. 1. baskı. İstanbul: Nobel Tip Kitabevi; 2015.

5. Gök Ş, Erölçer N, Özen C. Adli tıpta yaş tayini. 2. bask1, İstanbul: Adli Tıp Kurumu Yayınları; 1985.

6. Buran G, Aksu H. Child Age Marriages and The Effects on Women's Health: Literature Review. International Journal of Human Sciences 2018;15(2):1327-37. DOI: https://doi. org/10.14687/jhs.v15i2.5316

7. Boran P, Gökçay G, Devecioğlu E, Eren T. Çocuk Gelinler 2013;26(2):58-62. DOI: https://doi.org/10.5472/ MMJ.2013. 02751.1

8. Machel G, Pires E, Carlsson G. The World we Want: An End To Child Marriage. The Lancet. 2013;382(9897):10056. DOI: https://doi.org/10.1016/S0140-6736(13)61944-3

9. Aktepe E, Atay İM. Çocuk Evlilikleri ve Psikososyal Sonuçları. Psikiyatride Güncel Yaklasimlar. 2017;9(4):410-20. DOI: https://doi.org/10.18863/pgy.310791

10. Aydemir E. Evlilik mi evcilik mi? Erken ve zorla evlilikler: Çocuk gelinler. 1. baskı. Ankara: USAK Yayınları; 2011.

11. Marrying Too Young End Child Marriage. https://www.unfpa.org/end-child-marriage. (Erişim Tarihi: 15.01.2019)

12. Toplumsal Cinsiyet Göstergeleri Evlenme İstatistikleri. 2016, TÜİK. http://tuik.gov.tr/PreTablo.do?alt_id=1068 (Erişim Tarihi: 15.01.2019).

13. Yüksel Kaptanoğlu İ, Ergöçmen B. Çocuk Gelin Olmaya Giden Yol. Sosyoloji Araştırmaları Dergisi 2012;15(2):12861.

14. Türkiye'de Evlilik Tercihleri. 2015, Aile ve Sosyal Politikalar Bakanlığı Aile ve Toplum Hizmetleri Genel Müdürlüğü .https://ailetoplum.aile.gov.tr/uploads/pages/indirilebiliryayinlar/81-turkiye-de-evlilik-tercihleri-arastirmasi-2015. pdf (Erişim Tarihi: 15.01.2019)

15. World marriage patterns. 2011, United Nations Department of Economic and Social Affairs Population Division. https://www.un.org/en/development/desa/population/publications/pdf/popfacts/PopFacts_2011-1.pdf (Erişim Tarihi: 15.01.2019)

16. Türkiye Nüfus ve Sağlık Araştırmas1. 2013. http://www. hips.hacettepe.edu.tr/tnsa2013/rapor/TNSA_2013_ana_rapor.pdf. (Erişim Tarihi: 15.01.2019)

17. Hoşgör AG. Kadın Vatandaşlık Haklarındaki En Temel Sorun: "Nüfus Cüzdanım Yok Ki!". Toplum ve Demokrasi Dergisi 2014;2(4):27-38

18. Isır AB. Adli Hekimlikte Yaş Tayini. İstanbul Tabip Odası Klinik Gelişim Dergisi Adli Tıp Özel Sayısı 2009;22(1):114-21.

19. Yıldırım A, Çetin İ, Özer E, Gümüş B. Adli Tıp Anabilim Dalına 2006-2010 Yılları Arasında Yaş Tayini İçin Başvuran Olguların Değerlendirilmesi. Çağdaş Tıp Dergisi 2011;1(2):56-61.

20. Arslan MM, Çekin N, Akçan R, Saylak E. Hatay Ağır Ceza ve Asliye Hukuk Mahkemelerine 2007 Yılında Yansıyan Yaş Tespiti Davalarının İncelenmesi. Adli Tıp Dergisi 2008;22(2):8-13.

21. Büken B, Büken E, Şafak AA, Yazıcı B, Erkol Z, Mayda AS. Is the Gök Atlas sufficiently reliable for forensic age determination of Turkish children? Turk J Med Sci. 2008;38(4):319-327.

22. Özcebe H, Biçer BK. An İmportant Female Child And Woman Problem: Child Marriages. Turkish Pediatrics Archive. 2013;48(2):86-93. DOI: https://doi.org/10.4274/tpa.1907

23. Tuğrul YG. Erken Yaşta Evlendirilen Kadınların Evlilik Süreçleri, Deneyimleri ve Sonraki Yaşamları Üzerine Nitel Bir Çalışma. 15. Ulusal Sosyal Bilimler Kongresi; 29 Kasım-1 Aralık 2017; Ankara.

24. Yıdız N, Avcı H. Erken Evliliklerin Toplumsal Meşruiyeti: Nitel Bir Çalışma. http://www.ditam.org.tr/images/ Erken\%20Yasta\%20Evlililerin\%20Toplumsal\%20Mesruiyeti_1.pdf. (Erişim Tarihi: 15.01.2019)

25. Uskun E. Akraba Evlilikleri. STED 2001;10(2):54-6

26. Aile ve Sosyal Politikalar Bakanlığı Aile ve Toplum Hizmetleri Genel Müdürlüğü Türkiye Aile Yapısı Araştırmas1 2011. https://ailetoplum.aile.gov.tr/uploads/pages/ indirilebilir-yayinlar/65-aile-yapisi-arastirmasi. (Erişim Tarihi: 15.01.2019)

27. Erdinç D, Arslan G. Evlenmek Amacıyla Evden Kaçan Kız Ergenler: Bir Olgu Bilim Çalışması. Türk PDR Dergisi 2014;5(41):36-48.

28. Taylan HH. Türkiye'de Köy Ailesinde Aile İçi İlişkiler. SEFAD 2009;22:117-38. 